\title{
Germination and establishment of natural red spruce (Picea rubens) seedlings in silvicultural gaps of different sizes ${ }^{1}$
}

\author{
by Daniel Dumais ${ }^{2,3}$ and Marcel Prévost ${ }^{2}$
}

\begin{abstract}
Red spruce (Picea rubens Sarg.) is difficult to regenerate from natural seeding following silvicultural treatment. In order to study its germination and establishment, we monitored the dynamics of new seedlings over 10 years in silvicultural gaps of different sizes (small: $<100 \mathrm{~m}^{2}$, medium: $100-300 \mathrm{~m}^{2}$, large: $>700 \mathrm{~m}^{2}$ ). Seedling density was higher in small gaps but survival rate did not exceed $40 \%$, leaving few live seedlings after 10 years $\left(<200 \mathrm{ha}^{-1}\right)$. Mounds were the best microtopography for seedlings. Our results confirm the important role of decaying wood and moss for understory germination and establishment. Decaying wood was important for the establishment in large gaps while humus was more favourable in medium gaps. In small gaps, germinants and established seedlings were found as much on moss as humus and decaying wood. However, low observed densities suggest that planting in small or medium gaps should be explored for accelerating species renewal, especially if advance regeneration is deficient.
\end{abstract}

Keywords: Decaying wood, microsites, natural regeneration, red spruce (Picea rubens), seedbeds, silvicultural gaps.

\section{RÉSUMÉ}

Lépinette rouge (Picea rubens Sarg.) est difficile à régénérer par ensemencement naturel après une intervention sylvicole. Pour étudier sa germination et son établissement, nous avons suivi durant 10 ans la dynamique des nouveaux semis dans des trouées sylvicoles de différentes tailles (petites : $<100 \mathrm{~m}^{2}$, moyennes : 100-300 $\mathrm{m}^{2}$, grandes : $>700 \mathrm{~m}^{2}$ ). La densité de semis a été plus élevée dans les petites trouées, mais le taux de survie naa pas dépassé $40 \%$, laissant peu de semis vivants après 10 ans $\left(<200 \mathrm{ha}^{-1}\right)$. Les buttes ont été la meilleure microtopographie pour les semis. Nos résultats confirment le rôle important du bois en décomposition et de la mousse pour la germination et létablissement sous couvert. Le bois pourri sest avéré important pour létablissement dans les grandes trouées, alors que l'humus a été plus favorable dans les moyennes trouées. Dans les petites trouées, les germinants et les semis établis se trouvaient autant sur de la mousse que sur de l'humus ou du bois pourri. Cependant, les faibles densités observées suggèrent que la plantation dans de petites ou moyennes trouées soit une avenue à explorer afin d’accélérer le renouvellement de lespèce, d'autant plus si la régénération préétablie est déficiente.

Mots-clés : Bois en décomposition, épinette rouge (Picea rubens), lits de germination, microsites, régénération naturelle, trouées sylvicoles.

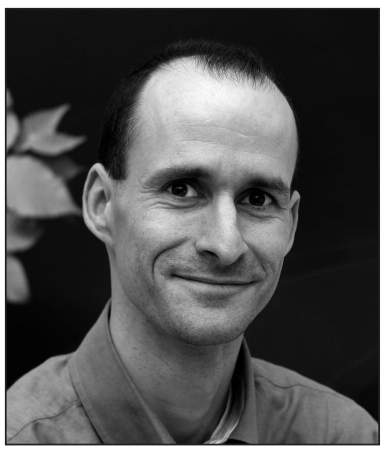

Daniel Dumais

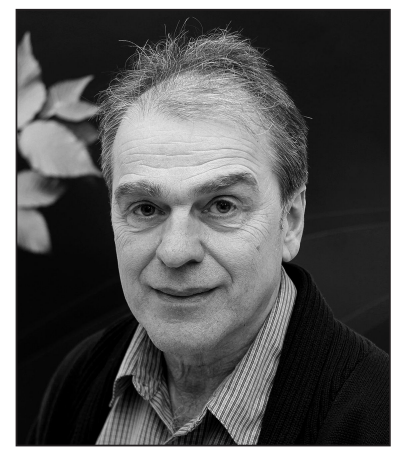

Marcel Prévost

\section{Introduction}

Red spruce (Picea rubens Sarg.) is a common forest species in northeastern North America. It can reach $25 \mathrm{~m}$ in height, $60 \mathrm{~cm}$ in diameter and 400 years of age (Farrar 1996). Its dense and resistant wood has long been appreciated (Dumais and Prévost 2013). Therefore, stands containing red spruce have always undergone pressure from the forest industry. In the past, silviculture did not necessarily focus on maintaining this companion species; given its particular autecology, red spruce is difficult to regenerate by natural seeding following silvicultural intervention (Dumais and Prévost 2007). Today, the known rarity of this species is an economic as well as a biodiversity issue with respect to forest composition (Grondin and Cimon 2003).

For red spruce, good seed crops occur every three to eight years (White and Cogbill 1992) and no seed bank exists in the

\footnotetext{
${ }^{1}$ English version of Dumais, D. et M. Prévost. 2015. Germination et établissement de semis naturels d'épinette rouge (Picea rubens) dans des trouées sylvicoles de différentes tailles. For. Chron. 91(5): 573-583.

${ }^{2}$ Ministère des Forêts, de la Faune et des Parcs du Québec, Direction de la recherche forestière, Service de la sylviculture et du rendement des forêts, 2700, rue Einstein, Québec (Québec) G1P 3W8 Canada

${ }^{3}$ Corresponding author e-mail: daniel.dumais@mffp.gouv.qc.ca
} 
soil (Cavallin and Vasseur 2008). Seeds on the ground are short-lived (maximum 12 months (Morgenstern and Farrar 1964) and are consumed by small mammals despite their very small size and scant nutrient reserves. To survive, young seedlings must have easy access to water and nutrients. However, since the species' roots are slow-growing and fine (Klein et al. 1991, Greenwood et al. 2008), young seedlings are fragile, show weak initial growth and have a high mortality rate. Furthermore, they are vulnerable to crushing by hardwood litter (Place 1955). As a result, red spruce seedlings struggle to compete and are very dependent on microtopography and seedbed type. According to some observations, raised microsites, such as old decaying stumps and coarse woody debris, could be favourable to seedling germination and establishment (Perkins 1991, Smallidge and Leopold 1994, Weaver et al. 2009). These microsites preserve humidity, do not accumulate much litter, and allow seedlings to rise above competing vegetation. Finally, deer browsing is another factor to consider (Kenefic et al. 2014).

Red spruce is very tolerant to shade. It can survive in the understory for several decades and resume vigorous growth after a partial canopy opening (Seymour 1995). This ecological characteristic is part of its regeneration strategy that consists in establishing, over time, a bank of seedlings and saplings in the understory. To survive under the canopy, red spruce features a high physiological tolerance and can morphologically adjust its crown architecture to low light conditions (Dumais and Prévost 2007). On the other hand, this adaptation does not allow it to acclimate quickly to sudden changes in environmental conditions (Dumais and Prévost 2008). Consequently, the species' regeneration process is closely dependent on the degree and speed of canopy opening. However, little is known about microsite and canopy opening conditions that are favourable to germination and establishment. Even when many new seedlings are present after a partial cutting, they usually disappear rapidly (Prévost and Charette 2015).

This study aims to characterise germination and establishment conditions of natural red spruce seedlings in small, medium and large silvicultural gaps. Our hypotheses are that: (1) seedling quantity and survival will be greater in smaller gaps; (2) gap size and conditions will influence seedling distribution and establishment success, according to important environmental variables (e.g., seedbed type); (3) growth of surviving seedlings will be optimal in large gaps; and, (4) seedlings will develop slowly, even in favourable conditions of partial canopy opening.

\section{Methodology \\ Study area}

The study was carried out in a yellow birch-conifer stand in the Appalachian Mountains $\left(46^{\circ} 50^{\prime} \mathrm{N}, 70^{\circ} 33^{\prime}\right.$, elevation: $400 \mathrm{~m}$ ), close to the municipality of Armagh about $50 \mathrm{~km}$ east of Québec City, Canada. The landscape is characterized by a flat topography and the soil is a humo-ferric podzol. Climate is continental, subpolar and subhumid. Annual mean temperature is $3.9^{\circ} \mathrm{C}\left(-12.8^{\circ} \mathrm{C}\right.$ in January and $18.5^{\circ} \mathrm{C}$ in July); annual precipitation averages $1167 \mathrm{~mm}$ with $23 \%$ as snow (MDDELCC 2015). Before cutting, the stand had a merchantable basal area (BA) of $31 \mathrm{~m}^{2} \mathrm{ha}^{-1}$ composed of yellow birch (Betula alleghaniensis Britt.; 37\%), red spruce (23\%), balsam fir (Abies balsamea (L.) Mill; 22\%), red maple (Acer rubrum L.; 15\%) and companion species (2\%) represented by paper birch (Betula papyrifera Marsh.) and striped maple (Acer pensylvanicum L.). Stand age and diameter structures were irregular and uneven-aged, and dominant trees had a mean height of $20 \mathrm{~m}$. Advance regeneration in the understory was red spruce and balsam fir.

\section{Experimental design}

A silvicultural experiment established in 2003 (Prévost and Charette 2015) was used for the present study. Each of the three replicates (blocks) contained four cutting treatments applied on $80 \times 80 \mathrm{~m}$ experimental units (EUs) - (i) small gaps: a uniform single-tree partial cut which created openings $<100 \mathrm{~m}^{2}$ with removal of $42 \%$ of overall BA; (ii) medium gaps: a hybrid treatment combining a uniform single-tree partial cut and a small group cut, which created three to five openings of irregular shape and size $\left(100\right.$ to $\left.300 \mathrm{~m}^{2}\right)$ with removal of $35 \%$ of overall BA; (iii) large gaps: a hybrid treatment combining a uniform single-tree partial cutting and a systematic patch cutting which created one circular $700-\mathrm{m}^{2}$ opening (30 m diameter) with removal of $40 \%$ of BA around the gap; and, (iv) a natural control without intervention. From a silvicultural viewpoint, removal of potentially dying trees between gaps with the hybrid approach would, among other things, increase residual stand vigor (Nyland 2002) and the profitability of the cutting operation. To maintain an adequate seed source for regeneration, almost all red spruce seed trees with a diameter at breast height $(\mathrm{DBH}) \geq 25 \mathrm{~cm}$ were spared from cutting. These trees were uniformly spread in the stand, with a mean density of 39 stems ha ${ }^{-1}$ and a mean DBH of $34 \mathrm{~cm}$.

\section{Light availability in gaps}

From June to October of the first six years after cutting, Prévost and Charette (2015) measured light availability in one of the experimental design's four blocks. Pyranometers (SPLITE, Kipp \& Zonen, Delft, Netherlands) were installed $1.3 \mathrm{~m}$ above the ground and connected to an automatic data acquisition system (CR10X, Campbell Scientific Canada, Edmonton, Alberta). In the control and small gap treatments, respectively, two and three pyranometers were placed close to the centre of the EU. In the medium and large gaps, five pyranometers were placed, one in the centre of the gap and four on the periphery, $5 \mathrm{~m}$ from the border at the four cardinal points.

\section{Sampling and measurements}

For the needs of this study, observations in each EU were made in a central $40 \mathrm{~m} \times 40 \mathrm{~m}$ subplot composed of a variable matrix of gaps and thinned stand created by the various treatments. New seedlings were inventoried during the first three years after cutting, i.e., when conditions created by canopy opening and soil disturbance were most favourable to spruce germination (Prévost and Pothier 2003). Indeed, beyond this period and until 10 years after cutting, we observed little or no red spruce recruitment since no other notable disturbance occurred in the limits of experimental design. During these three years, we located each new seedling (early in spring before vegetation season and late in the fall before the first snowfall) and identified them with metallic tags. To facilitate this task, we subdivided the subplot area into 16 sampling quadrats $(10 \mathrm{~m} \times 10 \mathrm{~m}$ each). 


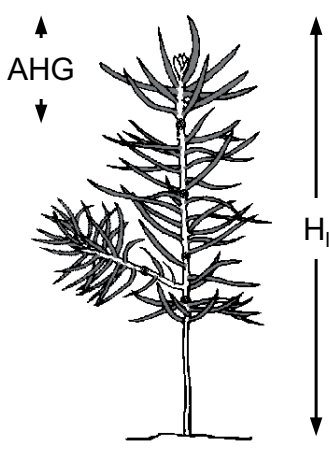

NLB $=1$

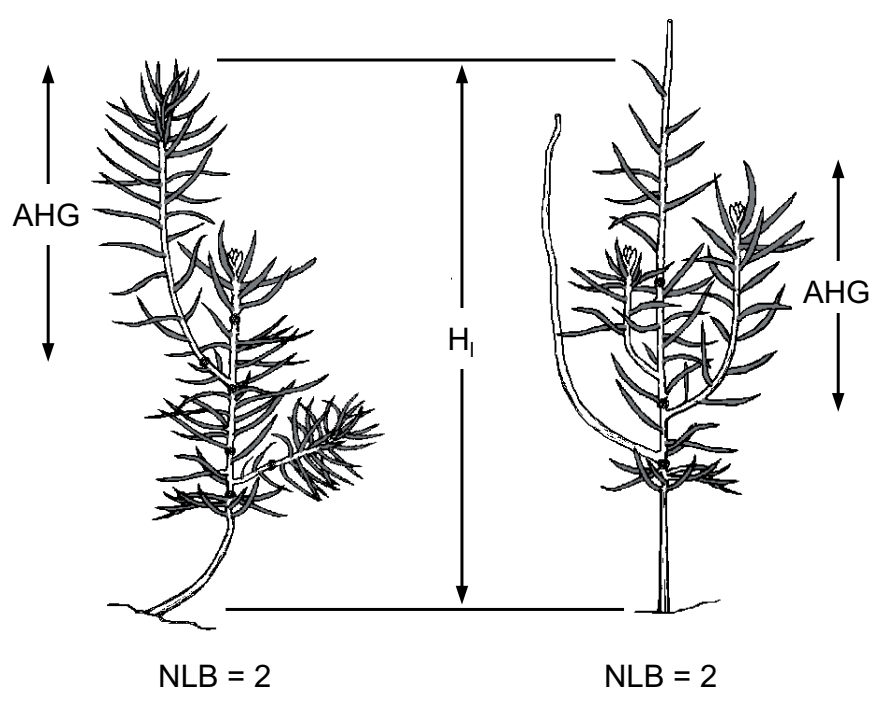

Fig. 1. Examples of measurements of annual height growth $(A H G)$, living height $\left(H_{l}\right)$ and number of living branches (NLB).

For each seedling, microtopography was classified according to three categories: (1) flat; (2) mound; and, (3) hollow. A difference of at least $15 \mathrm{~cm}$ relative to the surrounding ground level was used as criterion to determine if the seedling was located on a mound or in a hollow. The seedbed type was characterized according to four categories: (1) mineral soil, exposed or mixed with humus; (2) moss; (3) exposed humus; and, (4) decaying wood. Browsing occurrence was noted, regardless of its location on the seedling, and all competing vegetation was inventoried (species, height) in a $30-\mathrm{cm}$ radius around the seedling and up to a height of $1.5 \mathrm{~m}$.

To study seedling development, annual height growth (AHG) was measured during the first 10 years after cutting, calculated as the length of the highest annual shoot, i.e., the one most likely to ensure the vertical extension of the trunk (Fig. 1). This measurement was chosen because of the lack of architectural regularity and frequent breakage that affect the morphology of young seedlings (e.g., crushing by litter, browsing). Because AHG did not always equal annual height gain, height evolution was determined each year by measuring the living height $\left(\mathrm{H}_{1}\right)$, defined as the vertical distance between the highest ground level and the highest living leaf (Fig. 1).

In addition, the effects of browsing and of competing vegetation were monitored annually on all seedlings as described previously. Ten years after cutting, we also measured the collar diameter $\left(\right.$ Diam $\left._{C}\right)$ of each seedling and the number of living branches (NLB), defined as primary axes on the main stem (Fig. 1).

\section{Data treatment and statistical analyses}

At the end of year 3, initial density $\left(\mathrm{D}_{\text {ini }}\right)$ was calculated, defined as the number of seedlings inventoried during the first three years after cutting. Likewise, at the end of year 10, final density $\left(D_{\text {fin }}\right)$ was calculated in order to determine the decennial survival rate $\left(\mathrm{SR}_{10}\right)$, defined as the number of surviving seedlings divided by $\mathrm{D}_{\text {ini, }}$, expressed in $\%$. This simple calculation assumes that no new seedlings appeared after three years, as was observed in the field.
Data for $\mathrm{D}_{\text {ini, }}, \mathrm{D}_{\text {fin }}, \mathrm{SR}_{10}$, Diam $_{\mathrm{c}}, \mathrm{NLB}, \mathrm{AHG}$ and $\mathrm{H}_{1}$ were submitted to analyses of variance (ANOVAs) using the MIXED procedure of SAS software (version 9.3). AHG and $\mathrm{H}_{1}$ were analysed as repeated measurements in time on the same individuals. Multiple comparisons were tested (SIMULATE option) to verify the effect of gap size, and polynomial contrasts were used to interpret significant interactions between gap size and time.

Browsing pressure was included in the model as a qualitative variable with four modalities: (1) seedling not browsed; (2) seedling browsed for only one year; (3) for two years; or, (4) for three years or more. Likewise, dominant competing vegetation was included in the model according to five modalities: (1) seedling was not accompanied by competing vegetation; (2) seedling accompanied by hardwood tree species; (3) by conifers; (4) by ferns; or, (5) by raspberry. Height and density were used as criteria to determine the dominant competing vegetation for each seedling. Seedling distributions according to microtopography, seedbed, browsing occurrence and competing vegetation were submitted to distinct ANOVAs to verify the effect of gap size. Separated analyses were necessary because the data distributions did not allow an adequate testing of interactions between the different environmental variables.

To study how environmental variables affected seedling survival and development, $\mathrm{SR}_{10}$ and $\mathrm{AHG}$ were recalculated according to microtopography, seedbed type, browsing occurrence and competing vegetation. We then conducted distinct ANOVAs for each gap size and environmental variable.

For statistical tests, we used a 0.05 probability threshold to declare that an effect was significant. Variance homogeneity and normality of residuals were verified graphically. Mathematic transformations were used when necessary to satisfy the assumption of homoscedasticity (natural logarithm for AHG). Data were transformed back to their original scale to present results. 
Table 1. Structure of ANOVA and probabilities $(p>F)$ associated with gap size (Control: without gaps; Small: < $100 \mathrm{~m}^{2}$; Medium: 100-300 $\mathrm{m}^{2}$ with irregular form; Large: $700 \mathrm{~m}^{2}$, circular) on initial density $\left(D_{\text {ini, }}\right.$ year 3$)$ and final density $\left(D_{\text {fin }}\right.$, year 10$)$ of seedlings, survival rate $\left(\mathbf{S R}_{10}\right.$ ), collar diameter (Diam ${ }_{\mathrm{c}}$, year 10 ) and number of living branches (NLB, year 10$)$.

\begin{tabular}{|c|c|c|c|c|c|c|c|}
\hline \multirow[b]{2}{*}{ Source of variation } & \multirow[b]{2}{*}{$\mathrm{dfn}^{1}$} & \multirow[b]{2}{*}{$\mathrm{dfd}^{2}$} & \multicolumn{3}{|c|}{$p$} & \multirow[b]{2}{*}{$\operatorname{Diam}_{c}$} & \multirow[b]{2}{*}{ NLB } \\
\hline & & & $\mathrm{D}_{\mathrm{ini}}$ & $\mathrm{D}_{\text {fin }}$ & $\mathrm{SR}_{10}$ & & \\
\hline Gap size & 3 & 6 & 0.009 & 0.023 & $<0.001$ & $<0.001$ & 0.004 \\
\hline Control vs. Small & 1 & 6 & 0.010 & 0.017 & 0.002 & 0.016 & 0.102 \\
\hline Control vs. Medium & 1 & 6 & 0.830 & 0.040 & $<0.001$ & 0.035 & 0.230 \\
\hline Control vs. Large & 1 & 6 & 0.877 & 0.561 & 0.107 & 0.001 & 0.003 \\
\hline Small vs. Medium & 1 & 6 & 0.023 & 0.037 & 0.167 & 0.861 & 0.880 \\
\hline Small vs. Large & 1 & 6 & 0.020 & 0.026 & 0.027 & 0.009 & 0.028 \\
\hline Medium vs. Large & 1 & 6 & 0.999 & 0.048 & 0.002 & 0.004 & 0.014 \\
\hline
\end{tabular}

${ }^{1} \mathrm{dfn}$ : degrees of freedom of numerator.

${ }^{2} \mathrm{dfd}$ : degrees of freedom of denominator (example for $\mathrm{D}_{\text {ini }}$ ).

\section{Results}

Light availability in gaps

During the first six years after cutting, mean light availability increased with canopy opening, with values of $1.5,3.9,4.9$ and $8.9 \mathrm{MJ} \mathrm{m}^{-2} \mathrm{~d}^{-1}$ in the control treatment and in small, medium and large gaps, respectively.

\section{Density and survival according to gap size}

Initial density $\left(\mathrm{D}_{\text {ini }}\right)$ of spruce seedlings was greater (534 seedlings ha ${ }^{-1}$ ) in small gaps than in the control treatment (135) and larger gaps (196-198) $(p \leq 0.023$, Table 1 , Fig. 2a). Survival decreased rapidly during year 4 to year 6 , thereafter more slowly (Fig. 2b). Gap size had an effect on $\mathrm{SR}_{10}$, barely reaching $23 \%$ in large gaps, a value that did not significantly differ from the $16 \%$ observed in the control $(p=0.107$, Table 1$) . \mathrm{SR}_{10}$ was better in small $(32 \%)$ and medium (38\%) gaps than in large gaps ( $p \leq 0.027$, Fig. $2 b)$. By year $10, D_{\text {fin }}$ was thus highest in small gaps (173 seedlings ha${ }^{1}$ ), intermediate in medium gaps (76), lowest in large gaps (45) and in the control (21) ( $p \leq 0.037$, Table 1, Fig. 2a).

\section{Microtopography}

There were no seedlings in hollows. At year 3, the proportion of seedlings on mounds decreased as gap size increased (Fig. 3a); it was higher in the control treatment than in gaps $(p \leq 0.001$, Table 2a), and higher in smaller than in larger gaps $(p=0.010)$. Conversely, the proportion of seedlings on flat microtopography increased with gap size; it was lower in the control treatment than in medium and large gaps $(p \leq 0.005)$, and lower in small and medium gaps than in large gaps $(p \leq 0.008)$. Overall, the pattern observed according to gap size remained by year 10 . However, because survival was better on mounds ( $p \leq 0.044$, Table 3a, Fig. 4a), $60 \%$ of surviving seedlings occupied this microtopography (Fig. 3a). The control treatment stood out from the other treatments $(p<0.001$, not shown) with $95 \%$ of seedlings on mounds.

\section{Seedbed type}

By year 3 the proportion of seedlings on decaying wood or moss had decreased as gap size increased (Fig. 3b). The proportion of seedlings on wood was higher in the control treatment than in gaps ( $p \leq 0.041$, Table $2 \mathrm{~b})$, and higher in small gaps than in large ones $(p=0.027)$. Moreover, the proportion
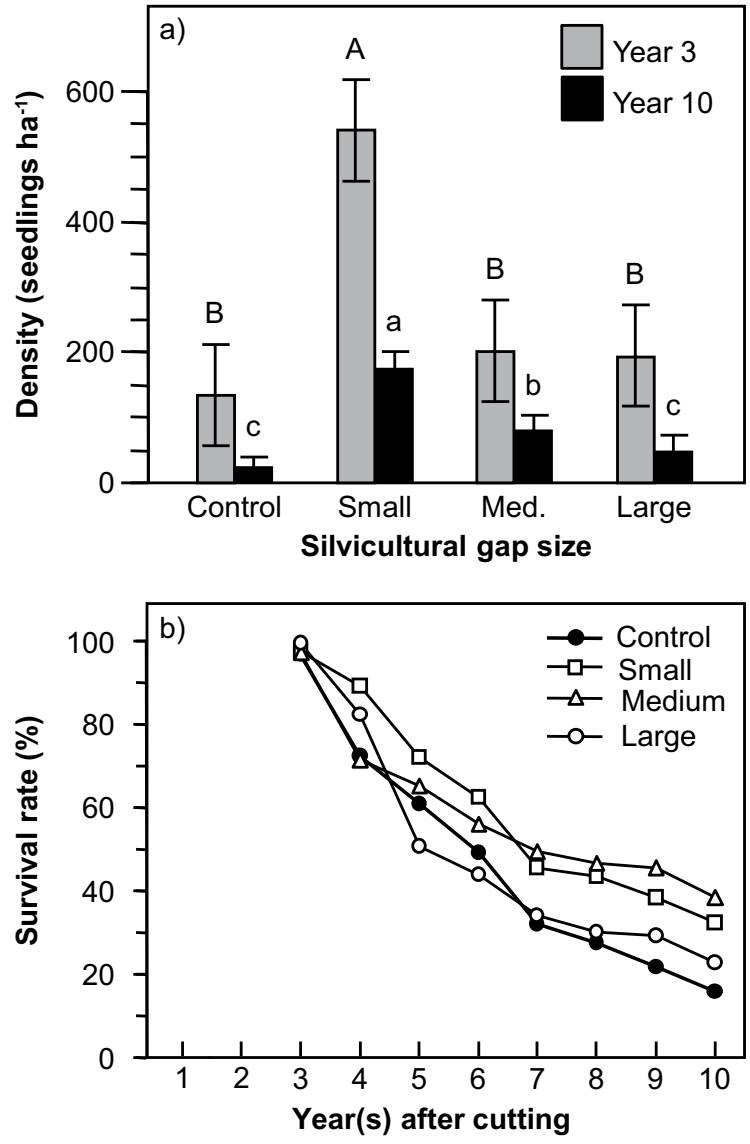

Fig. 2. a) Effect of gap size (see Table 1) on initial density (year 3 ) and final density (year 10). For the same year, columns with the same letter do not differ significantly. Vertical bars show standard error. b) Effects of gap size on annual seedling survival rate. Maximum standard error is $\pm 2 \%$. 


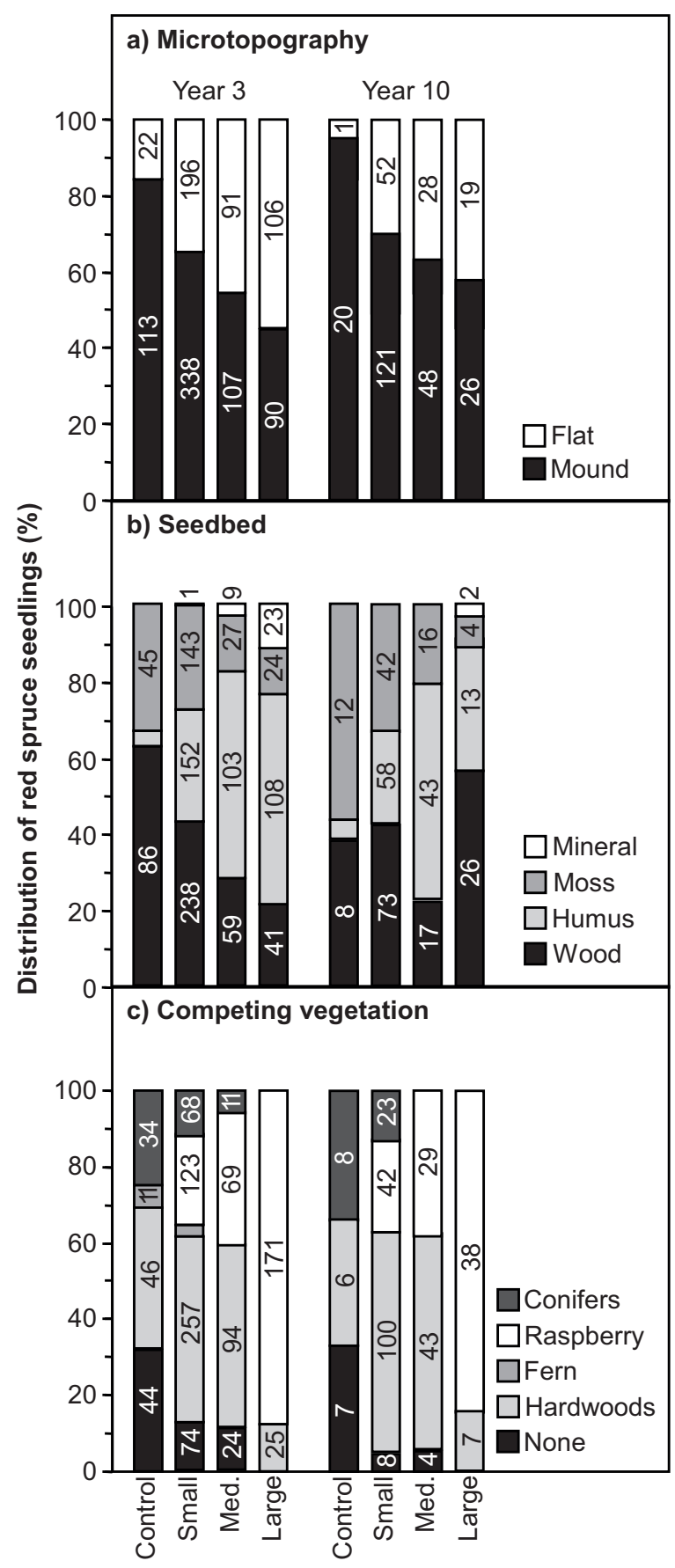

Silvicultural gap size

Fig. 3. Effects of gap size (see Table 1) on seedling distribution depending on a) microtopography, b) seedbed type and c) dominant competing vegetation. Maximum standard error is $\pm 3 \%$ for microtopography, $\pm 4 \%$ for seedbed type and $\pm 6 \%$ for competing vegetation. Numbers on columns indicate densities (seedlings/ha). Because of space constraints, the following densities are not indicated: b) humus in control: 4 for year 3) and 1 for year 10; c) ferns in small gaps: 12 for year 3 ). of seedlings on moss was higher in the control treatment than in medium and large gaps $(p \leq 0.001)$, and higher in small gaps than in larger gaps $(p \leq 0.017)$. Conversely, the proportion of seedlings on humus increased with gap size by year 3 (Fig. 3b). It was much lower in the control treatment than in gaps $(p \leq 0.002)$, and lower in small gaps than in larger gaps $(p \leq 0.004)$. Seedlings were found on mineral soil only in large gaps, and only in a low proportion (10\%) by year 3; their survival was negligible after 10 years (Figs. $3 \mathrm{~b}$ and $4 \mathrm{~b}$ ). Survival dynamics by year 10 followed different patterns depending on gap size (Fig. 3b). In large gaps, because of better survival on decaying wood ( $p \leq 0.038$, Table $3 \mathrm{~b}$, Fig. $4 \mathrm{~b}$ ), $60 \%$ of surviving seedlings were found on this seedbed than on humus (year 3).

\section{Browsing occurrence}

The proportion of seedlings exempt from browsing during the 10-year observation period was higher in the control treatment $(70 \%)$ than in gaps $(50 \%)(p \leq 0.050$, Table $2 c$, not illustrated). Browsing occurrence did not seem to affect seedling survival ( $p \geq 0.118$, Table $3 c)$.

\section{Dominant competing vegetation}

The proportion of seedlings free of competing vegetation during the 10-year period was higher in the control treatment than in small and medium-sized gaps $(p \leq 0.035$, Table $2 \mathrm{~d}$, Fig. 3c). In large gaps, all seedlings were exposed to competing vegetation, and raspberry was the dominant competitor in almost all cases. In addition, the proportion of seedlings competing with raspberry was similar in small and medium gaps, but higher in large gaps $(p \leq 0.027)$. Likewise, the proportion of seedlings competing with hardwood species was similar in the control treatment and in small and medium gaps, but much lower in large gaps $(p \leq 0.007)$. Conifers were competitors for a significant proportion of seedlings only in the control treatment $(p \leq 0.048)$. Because the type of competing vegetation did not affect survival (Fig. 4c), seedling distribution patterns were mostly unchanged by year 10 (Fig. 3c). Nevertheless, in small and medium gaps, seedlings that were free of competing vegetation occupied significantly less space in year 10 than in year $3(p \leq 0.032)$, because their $\mathrm{SR}_{10}$ was lower than those of seedlings accompanied by competing vegetation ( $p \leq 0.044$, Table 3d, Fig. $4 c)$.

\section{Growth variables according to gap size}

After 10 years, Diam ${ }_{c}$ and NLB were related to gap size. $\operatorname{Diam}_{\mathrm{c}}(24 \mathrm{~mm}$ to $40 \mathrm{~mm}$ ) was greater in gaps than in the control treatment $(14 \mathrm{~mm})(p \leq 0.035$, Table 1$)$. NLB, on the other hand, was higher in large gaps (12) than in smaller gaps (6-7) and in the control treatment (3) ( $p \leq 0.028)$.

The interaction between gap size and time affected AHG $(p<0.001$, Table 4$)$, was generally greater in gaps $\left(2 \mathrm{~cm}_{\text {year }}^{-}\right.$ ${ }^{1}$ to $\left.4 \mathrm{~cm} \mathrm{year}^{-1}\right)$ than in the control treatment $\left(1 \mathrm{~cm}_{\text {year }}{ }^{-1}\right)$, and greater in large gaps than in smaller gaps (Fig. 5a). This interaction indicates that the difference between the control treatment and small and medium gaps decreased over time $(p \leq 0.003)$, so that by year 10 , height growth of seedlings in small and medium gaps was as low as in the control treatment (Fig. 5a). Conversely, the difference in AHG between seedlings in large gaps and in the control treatment $\left(+3 \mathrm{~cm}\right.$ year $\left.^{-1}\right)$ was maintained but it increased between seedlings in large gaps and in other treatments $(p \leq 0.047)$. 
Table 2. Structure of ANOVA and probabilities ( $p>$ F) associated with the effects of gap size (see Table 1) on seedling distribution depending on environmental variables: microtopography (year 3; year 10 not shown), seedbed type (year 3; year 10 not shown), 10 -year browsing occurrence and competing vegetation (year 3; year 10 not shown).

\begin{tabular}{lcccc}
\hline & & & \multicolumn{2}{c}{ a) Microtopography } \\
\cline { 4 - 5 } Source of variation & dfn $^{\mathbf{1}}$ & $\mathbf{d f d}^{\mathbf{2}}$ & Mounds & Flat \\
\hline Gap size & 3 & 8 & $<0.001$ & $<0.001$ \\
Control vs. Small & 1 & 8 & 0.001 & 0.071 \\
Control vs. Medium & 1 & 8 & $<0.001$ & 0.005 \\
Control vs. Large & 1 & 8 & $<0.001$ & $<0.001$ \\
Small vs. Medium & 1 & 8 & 0.134 & 0.163 \\
Small vs. Large & 1 & 8 & 0.010 & $<0.001$ \\
Medium vs. Large & 1 & 8 & 0.295 & 0.008
\end{tabular}

b) Seedbed type

\begin{tabular}{|c|c|c|c|c|c|c|}
\hline & & & \\
\hline & & & Wood & Moss & Humus & Mineral \\
\hline Gap size & 3 & 8 & 0.001 & $<0.001$ & $<0.001$ & - \\
\hline Control vs. Small & 1 & 8 & 0.041 & 0.244 & 0.002 & - \\
\hline Control vs. Medium & 1 & 8 & 0.002 & 0.001 & $<0.001$ & - \\
\hline Control vs. Large & 1 & 8 & 0.001 & $<0.001$ & $<0.001$ & - \\
\hline Small vs. Medium & 1 & 8 & 0.124 & 0.017 & 0.004 & - \\
\hline Small vs. Large & 1 & 8 & 0.027 & 0.003 & 0.002 & - \\
\hline Medium vs. Large & 1 & 8 & 0.666 & 0.577 & 0.954 & - \\
\hline
\end{tabular}

c) Browsing occurrence

\begin{tabular}{|c|c|c|c|c|c|c|}
\hline & & & \\
\hline & & & None & 1 year & 2 years & 3 years + \\
\hline Gap size & 3 & 8 & 0.016 & 0.470 & 0.281 & 0.464 \\
\hline Control vs. Small & 1 & 8 & 0.017 & 0.718 & 0.743 & 0.627 \\
\hline Control vs. Medium & 1 & 8 & 0.032 & 0.940 & 0.234 & 0.677 \\
\hline Control vs. Large & 1 & 8 & 0.050 & 0.987 & 0.829 & 0.441 \\
\hline Small vs. Medium & 1 & 8 & 0.932 & 0.417 & 0.655 & 1.000 \\
\hline Small vs. Large & 1 & 8 & 0.746 & 0.886 & 0.998 & 0.984 \\
\hline Medium vs. Large & 1 & 8 & 0.973 & 0.808 & 0.564 & 0.971 \\
\hline
\end{tabular}

d) Competing vegetation

\begin{tabular}{|c|c|c|c|c|c|c|}
\hline & & & & & & \\
\hline & & & None & Hardwoods & Raspberry & Conifers \\
\hline Gap size & 2 & 4 & 0.025 & 0.001 & 0.009 & 0.011 \\
\hline Control vs. Small & 1 & 4 & 0.035 & 0.235 & - & 0.048 \\
\hline Control vs. Medium & 1 & 4 & 0.029 & 0.295 & - & 0.009 \\
\hline Control vs. Large & 1 & 4 & - & 0.007 & - & - \\
\hline Small vs. Medium & 1 & 4 & 0.962 & 0.998 & 0.757 & 0.370 \\
\hline Small vs. Large & 1 & 4 & - & 0.001 & 0.012 & - \\
\hline Medium vs. Large & 1 & 4 & - & 0.001 & 0.027 & - \\
\hline
\end{tabular}

${ }^{1} \mathrm{dfn}$ : degrees of freedom of numerator (example for the first variable).

${ }^{2} \mathrm{dfd}$ : degrees of freedom of denominator (example for the first variable).

The patterns observed for AHG led to differences in seedling $\mathrm{H}_{1}$ according to gap size and over time. On average, for the 10-year period, seedlings were taller in gaps $(13 \mathrm{~cm})$ than in the control treatment $(7 \mathrm{~cm})(p \leq 0.046$, Table 4 , Fig. 5b), and taller in large gaps $(16 \mathrm{~cm})$ than in small gaps $(11 \mathrm{~cm})(p \leq 0.029)$.

\section{Environmental variables influencing height growth}

Microtopography had a significant effect only in medium gaps where seedling $\mathrm{AHG}$ was $1 \mathrm{~cm}$ year $^{-1}$ greater on flat microtopography than on mounds $(p=0.017$, not shown,
Fig. 6a). In small gaps, humus or moss seedbeds were more favourable to seedling AHG (+1 $\left.\mathrm{cm}_{\text {year }}{ }^{-1}\right)$ than decaying wood ( $p \leq 0.047$, Fig. 6b). In medium gaps, humus was more favourable $\left(+1 \mathrm{~cm} \mathrm{year}^{-1}\right)$ than the others $(p \leq 0.025)$, whereas in large gaps, moss was the most beneficial (up to $+1 \mathrm{~cm}$ year $^{-1}, p \leq 0.036$ ). Finally, in small and medium gaps, seedlings accompanied by hardwood species or raspberry had a greater AHG $\left(+1 \mathrm{~cm}_{\text {year }}{ }^{-1}\right)$ than those without competing vegetation or those accompanied by conifers $(p \leq 0.023$, Fig. 6c) 
Table 3. Structure of ANOVA and probabilities $(p>F)$ associated with the effects of environmental variables on decennial survival rate $\left(\mathbf{S R}_{10}\right.$ ) of seedlings by gap size (see Table 1 ).

\begin{tabular}{|c|c|c|c|c|c|c|c|c|c|c|c|c|}
\hline \multirow[b]{3}{*}{ Source of variation } & \multicolumn{12}{|c|}{ Silvicultural gap size } \\
\hline & \multicolumn{3}{|c|}{ Control } & \multicolumn{3}{|c|}{ Small } & \multicolumn{3}{|c|}{ Medium } & \multicolumn{3}{|c|}{ Large } \\
\hline & $\mathrm{dfn}^{1}$ & $\mathrm{dfd}^{2}$ & $p$ & dfn & dfd & $p$ & dfn & dfd & $p$ & dfn & dfd & $p$ \\
\hline \multicolumn{13}{|l|}{ a) Microtopography } \\
\hline Mounds vs. Flat & 1 & 2.0 & 0.015 & 1 & 2.3 & 0.043 & 1 & 2.0 & 0.039 & 1 & 2.0 & 0.044 \\
\hline \multicolumn{13}{|l|}{ b) Seedbed type } \\
\hline Wood vs. Humus & 1 & 4.0 & 0.590 & 1 & 6.0 & 0.682 & 1 & 4.0 & 0.646 & 1 & 3.0 & 0.038 \\
\hline Wood vs. Moss & 1 & 4.0 & 0.304 & 1 & 6.0 & 0.984 & 1 & 4.0 & 0.235 & 1 & 2.9 & 0.031 \\
\hline Wood vs. Mineral & - & - & - & - & - & - & - & - & - & 1 & 3.0 & 0.016 \\
\hline Humus vs. Moss & 1 & 4.0 & 0.891 & 1 & 6.0 & 0.577 & 1 & 4.0 & 0.579 & 1 & 3.0 & 0.892 \\
\hline Humus vs. Mineral & - & - & - & - & - & - & - & - & - & 1 & 2.9 & 0.623 \\
\hline Moss vs. Mineral & - & - & - & - & - & - & - & - & - & 1 & 3.0 & 0.457 \\
\hline \multicolumn{13}{|l|}{ c) Browsing occurrence } \\
\hline None vs. 1 year & 1 & 4.5 & 0.997 & 1 & 8.0 & 0.999 & 1 & 5.4 & 0.933 & 1 & 6.0 & 0.999 \\
\hline None vs. 2 years & 1 & 4.9 & 0.618 & 1 & 8.0 & 0.627 & 1 & 5.4 & 0.964 & 1 & 6.0 & 0.990 \\
\hline None vs. 3 years+ & 1 & 4.9 & 0.933 & 1 & 8.0 & 0.474 & 1 & 5.8 & 0.190 & 1 & 6.0 & 0.998 \\
\hline 1 year vs. 2 years & 1 & 4.9 & 0.707 & 1 & 8.0 & 0.580 & 1 & 5.3 & 0.728 & 1 & 6.0 & 0.972 \\
\hline 1 year vs. 3 years+ & 1 & 4.9 & 0.870 & 1 & 8.0 & 0.430 & 1 & 5.7 & 0.342 & 1 & 6.0 & 0.987 \\
\hline 2 years vs. 3 years + & 1 & 4.5 & 0.409 & 1 & 8.0 & 0.993 & 1 & 5.7 & 0.118 & 1 & 6.0 & 1.000 \\
\hline \multicolumn{13}{|l|}{ d) Competing vegetation } \\
\hline None vs. Hardwoods & 1 & 6.0 & 0.788 & 1 & 6.0 & 0.018 & 1 & 4.0 & 0.041 & - & - & - \\
\hline None vs. Conifers & 1 & 6.0 & 0.594 & 1 & 6.0 & 0.036 & - & - & - & - & - & - \\
\hline None vs. Raspberry & - & - & - & 1 & 6.0 & 0.039 & 1 & 4.0 & 0.044 & - & - & - \\
\hline Hardwoods vs. Conifers & 1 & 6.0 & 0.290 & 1 & 6.0 & 0.945 & - & - & - & - & - & - \\
\hline Hardwoods vs. Raspberry & - & - & - & 1 & 6.0 & 0.903 & 1 & 4.0 & 0.903 & 1 & 3.0 & 0.768 \\
\hline Raspberry vs. Conifers & - & - & - & 1 & 6.0 & 0.999 & - & - & - & - & - & - \\
\hline
\end{tabular}

${ }^{1} \mathrm{dfn}$ : degrees of freedom of numerator.

${ }^{2} \mathrm{dfd}$ : degrees of freedom of denominator.

\section{Discussion}

\section{Gap size effect on density of new seedlings}

Seedling densities were almost three times greater in small gaps than in larger gaps (Fig. 2a). This result confirms our first hypothesis that recruitment is better in small gaps $\left(<100 \mathrm{~m}^{2}\right)$, and also points to the light and soil disturbance conditions that favour germination and establishment. Apparently, moderate sunlight combined with mild soil disturbance is optimal. This finding supports those of other studies in favour of single-tree partial cutting (Dibble et al. 1999, Archambault et al. 2003, Prévost and Charette 2015), and contradicts the previous hypothesis stating that this treatment is too light to create suitable conditions for red spruce regeneration (e.g., Frank and Blum 1978).

Gap size effect on germination conditions and success (year 3) Our second hypothesis, i.e., that silvicultural gap size affects seedling distribution depending on environmental variables must be verified, keeping in mind that gap creation could influence these variables to various degrees. For example, the total area occupied by mineral soil increased with soil disturbance, which was more important in medium and large gaps (Prévost and Charette 2015). Therefore, the presence of new seedlings could partly reflect the increased availability of this seedbed type, rather than its greater receptivity for red spruce. The work of Prévost and Charette (2015), who studied coverage of the different seedbed types in the same experimental design, will help interpret these results.

The occupation of mounds and flat microtopography by seedlings followed sunlight and soil disturbance gradients resulting from the increase in gap size (Fig. 3a). In shade and undisturbed soil conditions of the control treatment, mounds were much more suitable to germination than the more readily available flat microtopography, possibly because of lower soil temperatures (Dwyer and Merriam 1981) and reduced litter accumulation (Ruel et al. 1988). However, in large 700 $\mathrm{m}^{2}$ gaps, seedlings initially colonized flat microtopography as well as mounds, possibly because of more constant water availability (Örlander et al. 1990) and of less extreme air and soil temperatures.

Literature highlights the importance of decaying wood as a privileged seedbed for red spruce (e.g., Weaver et al. 2009), particularly because of its good water retention (Fraver et al. 2002). Our study highlights the preference of red spruce for this type of seedbed in the control treatment. Indeed, even if this seedbed type covered only $9 \%$ of the understory area (Prévost and Charette 2015), more than 60\% of spruce seedlings would be found on this seedbed (Fig. 3b). Yet, the 


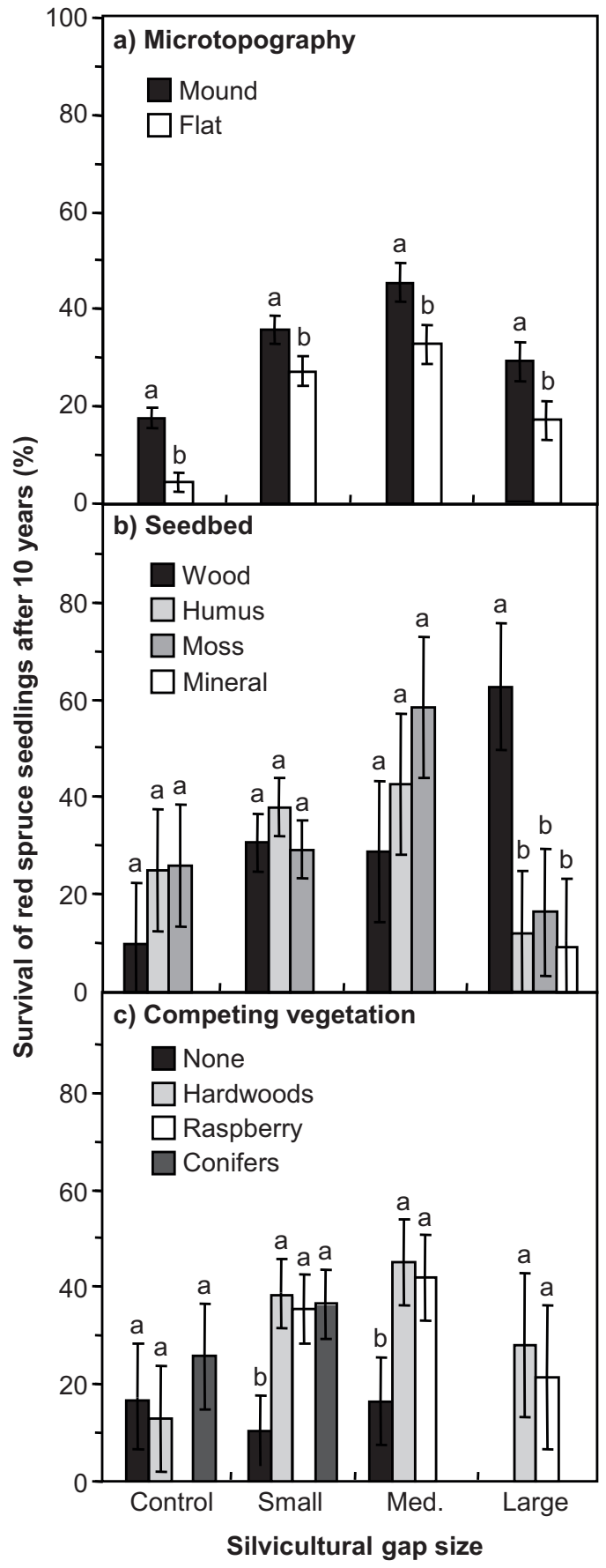

Fig. 4. Effects of a) microtopography, b) seedbed type and c) dominant competing vegetation on decennial survival rate (SR10) according to gap size (see Table 1). For each gap size, columns with the same letter do not differ significantly. Vertical bars show standard error.
Table 4. Structure of ANOVA and probabilities ( $p>F$ ) associated with gap size (see Table 1) and time (year 2 to year 10) on annual height growth $(A H G)$ and evolution of living height $\left[\mathrm{H}_{1}\right]$

\begin{tabular}{lcccc}
\hline Source of variation & $\mathbf{d f n}^{\mathbf{1}}$ & $\mathbf{d f d}^{\mathbf{2}}$ & AHG & $\mathbf{H}_{\mathbf{1}}$ \\
\hline Gap size & 3 & 8.0 & 0.001 & 0.011 \\
Control vs. Small & 1 & 7.9 & 0.018 & 0.042 \\
Control vs. Medium & 1 & 8.0 & 0.041 & 0.046 \\
Control vs. Large & 1 & 8.0 & $<0.001$ & 0.001 \\
Small vs. Medium & 1 & 7.9 & 0.935 & 0.956 \\
Small vs. Large & 1 & 8.1 & 0.040 & 0.029 \\
Medium vs. Large & 1 & 7.9 & 0.018 & 0.026 \\
Time $(\mathrm{T})$ & 8 & 26.2 & $<0.001$ & $<0.001$ \\
Gap size $\times$ T & 24 & 47.4 & $<0.001$ & 0.144 \\
Control vs. Small $\times \mathrm{T}$ & 1 & 44.6 & 0.003 & - \\
Control vs. Medium $\times \mathrm{T}$ & 1 & 61.5 & $<0.001$ & - \\
Control vs. Large $\times \mathrm{T}$ & 1 & 55.9 & 0.249 & - \\
Small vs. Medium $\times \mathrm{T}$ & 1 & 44.2 & 0.010 & - \\
Small vs. Large $\times \mathrm{T}$ & 1 & 62.3 & 0.001 & - \\
Medium vs. Large $\times \mathrm{T}$ & 1 & 45.0 & 0.047 & - \\
\hline
\end{tabular}

${ }^{1} \mathrm{dfn}$ : degrees of freedom of numerator.

${ }^{2} \mathrm{dfd}$ : degrees of freedom of denominator (example for AHG)

proportion of seedlings on decaying wood decreased with increasing canopy opening. This could be due partly to a lower availability of this seedbed type (5\% of area in medium and large gaps), and partly to its reduced water content. With more exposition to sunlight, some wood decay stages may not have maintained favourable humidity for red spruce germination (see Robert et al. 2012). Therefore, the interaction between gap size and wood at different stages of decay possibly better explains the germination success of red spruce than the sole presence of decaying wood. This hypothesis remains to be verified. Furthermore, our results indicate that humus would be more favourable to red spruce germination in medium and large gaps (Fig. 3b). Indeed, although humus occupied only $2 \%$ to $5 \%$ of these gaps $(7 \%-13 \%$ for mineral soil and 4\%-5\% for decaying wood; Prévost and Charette 2015), we observed more than $50 \%$ of red spruce seedlings on this seedbed type.

Since it depends on sunlight conditions, soil humidity, and temperature, competing vegetation was also influenced by gap size. For example, the area covered by raspberry reached $23 \%$ in medium gaps and $44 \%$ in large gaps (Prévost and Charette 2015). In large gaps, although $56 \%$ of the area was occupied by other species or no vegetation, red spruce seedlings were almost always accompanied by raspberry (Fig. 3c). Since red spruce does not tolerate extreme conditions (Dumais and Prévost 2007), raspberry cover may have tempered the microclimate around the seedlings (Man and Greenway 2011, Hyppönen et al. 2013).

\section{Establishment (year 10), growth and driving factors}

After germination, seedlings must survive and develop (establishment stage), otherwise their future is uncertain. Yet the conditions favourable to germination and initial survival (Pauley 1993) do not necessarily favour mid- or long-term establishment and growth (Takahashi et al. 2000, Burgess and Wetzel 2002, Prévost and Dumais 2003). In the present study, relatively high initial density and survival allowed red spruce 


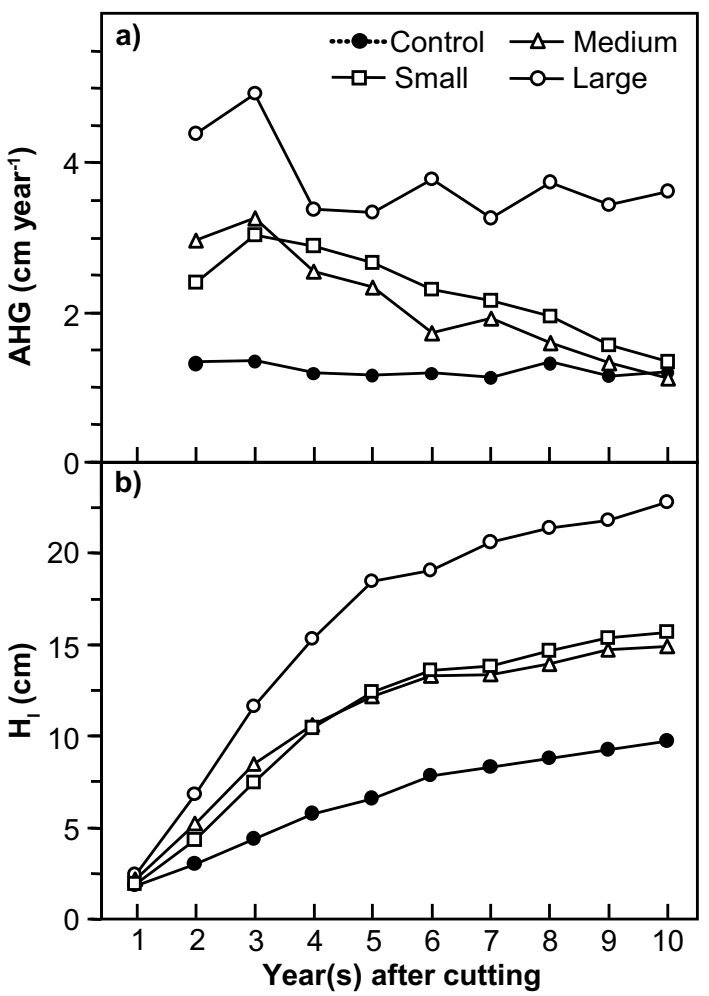

Fig. 5. Effects of gap size (see Table 1) and time on a) annual height growth $(\mathrm{AHG})$ and $\mathbf{b})$ evolution of living height $\left(\mathrm{H}_{1}\right)$. Maximum standard error is $\pm 0.2 \mathrm{~cm}$ year -1 for $A H G$ and $\pm 2.0 \mathrm{~cm}$ for $\mathrm{HI}$.

seedlings in small gaps $\left(<100 \mathrm{~m}^{2}\right)$ to have the best establishment, despite moderate growth. Conversely, extreme conditions in both the control and in large gaps $\left(700 \mathrm{~m}^{2}\right)$ reduced seedling survival and subsequent establishment in these two contrasting regeneration niches. However, values of growth variables (Diam, NLB, AHG and $\mathrm{H}_{1}$ ) were higher in large gaps, where sunlight was more available. This confirms our third hypothesis and reiterates that red spruce, once it is established, needs an increase in sunlight to optimise its growth (Seymour 1995, Dumais and Prévost 2008, 2014; Greenwood et al. 2008).

Analysis of environmental variables allowed us to identify conditions that influence survival and growth of red spruce seedlings (hypothesis 2). For all gap sizes, survival was best on mounds (Fig. 4a), which accumulate less litter and keep seedlings above competing vegetation (see Dumais and Prévost 2007). However, in medium gaps $\left(100 \mathrm{~m}^{2}\right.$ to $\left.300 \mathrm{~m}^{2}\right)$, flat microtopography favoured height growth (Fig. 6a), probably due to better access to water and nutrients combined with acceptable sunlight and temperature conditions.

Seedbed type also affected seedling establishment. In large gaps, where regeneration was very exposed to sunlight, seedling survival clearly was better on decaying wood than on other seedbed types (Fig. 4b). Better water retention could explain better survival on decaying wood despite extreme evapotranspiration conditions in large gaps. This result supports Prévost and Charette's (2015) hypothesis that the lack of decaying wood partly explains establishment failure of red

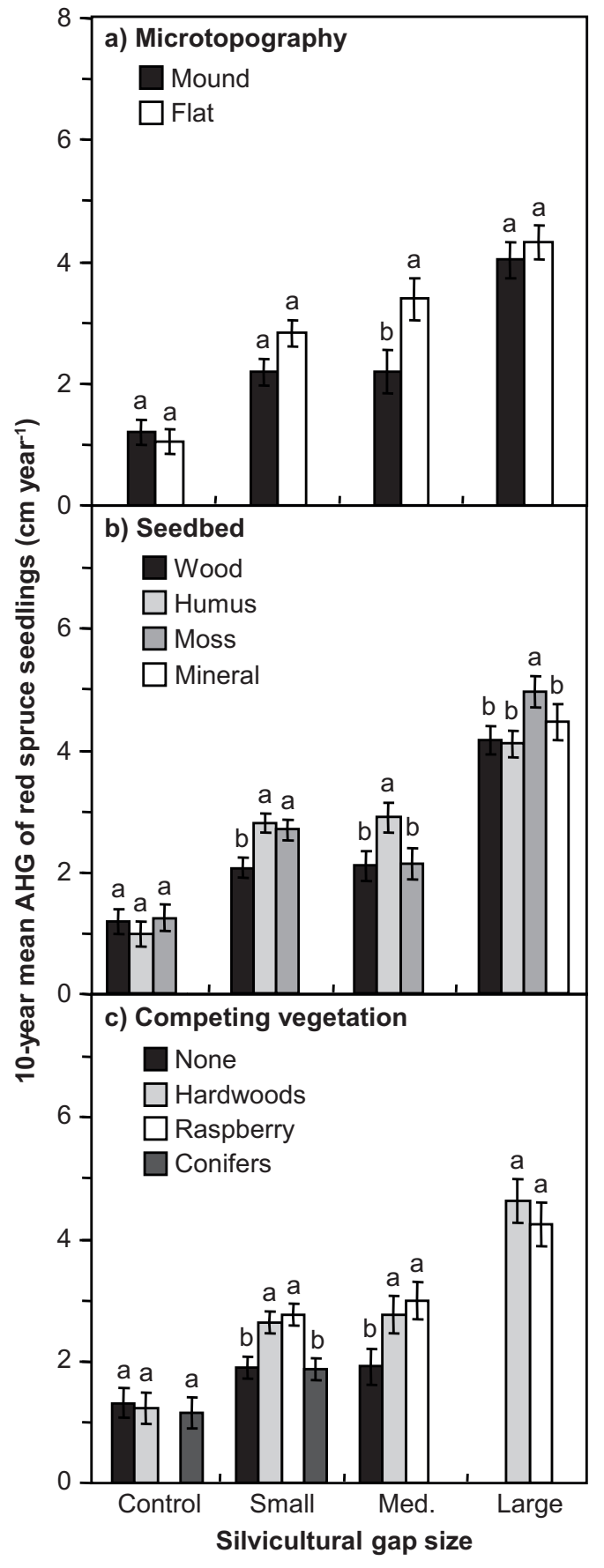

Fig. 6. Effects of a) microtopography, b) seedbed type and c] dominant competing vegetation on annual height growth (AHG) of red spruce seedlings depending on gap size (defined in Table 1). For each gap size, columns with the same letter do not differ significantly. Vertical bars show standard error.

spruce in this large gap regeneration niche. However, it should be mentioned that this moist seedbed type did not allow an optimal height growth in the present study (Fig. 6b), possibly because of low nutrient availability (Harmon et al. 1986). 
Regarding competing vegetation, we were surprised to note that hardwood species and raspberry, although the latter can be harmful to young conifers (Prévost et al. 2010, Prévost and Charette 2015), could favour establishment of spruce seedlings in small and medium gaps (Figs. $4 \mathrm{c}$ and $6 \mathrm{c}$ ). As previously mentioned, this could result from a shelter effect of this vegetation, which would limit microclimate variations.

In support of our last hypothesis, the data show that development of new seedlings is particularly slow. In medium gaps $\left(100 \mathrm{~m}^{2}\right.$ to $\left.300 \mathrm{~m}^{2}\right)$ simulating natural dynamics (Kneeshaw and Prévost 2007), height growth was only $2 \mathrm{~cm}$ year $^{-1}$. Unfortunately, to our knowledge no other research has examined growth of such young natural red spruce seedlings. This makes it difficult to compare our results.

\section{Conclusions and silvicultural implications}

Germination and establishment of red spruce depend on microenvironment, which is influenced by silvicultural practices. The degree of canopy opening plays an important role. Small silvicultural gaps $\left(<100 \mathrm{~m}^{2}\right)$ were by far more favourable to germination and establishment than medium (100-300 $\left.\mathrm{m}^{2}\right)$ or large $\left(700 \mathrm{~m}^{2}\right)$ gaps. Eventually however, larger gaps appear to be necessary for optimal seedling growth. These conditions concur with an irregular shelterwood cutting scenario (see Raymond et al. 2009). Moreover, the alarming decrease in seedling survival over the 10-year period (Fig. 2b) warrants caution during early regeneration inventories after cutting to avoid overestimating the potential density of red spruce seedlings.

This study confirms the major role of decaying wood and moss for red spruce germination and establishment in the understory. Decaying wood also proved necessary for the establishment of seedlings in large gaps as was humus in medium gaps. In small gaps, where conditions seem more homogenous, germinants and established seedlings were found equally on moss, humus and decaying wood.

In summary, to maximise natural regeneration of red spruce, foresters should create small gaps and retain decaying wood at different stages, particularly if gap enlargement is planned. Given the low densities and slow growth of seedlings observed in the present study, planting in small or medium gaps could be explored as a means to accelerate the species' renewal, especially where advance regeneration is deficient.

\section{Acknowledgments}

We thank two anonymous reviewers for their comments and suggestions that allowed us to improve this article. Technical field work by Julie Forgues, Carlo Gros-Louis, Daniel Guimond, Serge Williams, Pascal Lainé, Étienne Du Berger and many summer students was also greatly appreciated. We are also grateful to Josianne DeBlois for statistical advice. Finally, we thank Denise Tousignant for linguistic revision and edition. This research is part of projects 142332016 and 142332111 of the Direction de la recherche forestière (Ministère des Forêts, de la Faune et des Parcs du Québec).

\section{References}

Archambault, L., J. Bégin, C. Delisle and M. Fortin. 2003. Dynamique forestière après coupe partielle dans la Forêt expérimentale du Lac Édouard, Parc de la Mauricie, Québec. Forest. Chron. 79: 672-684.
Burgess, D. and S. Wetzel. 2002. Recruitment and early growth of eastern white pine (Pinus strobus) regeneration after partial cutting and site preparation. Forestry 75: 419-423.

Cavallin, N. and L. Vasseur. 2008. Potential for red spruce (Picea rubens Sarg.) establishment from natural seed dispersal in old fields adjacent to forest stands. Plant Ecol. 199: 33-41.

Dibble, A.C., J.C. Brissette and M.L. Hunter Jr. 1999. Putting community data to work: some understory plants indicate red spruce regeneration habitat. Forest Ecol. Manag. 114: 275-291.

Dumais, D. and M. Prévost. 2007. Management for red spruce conservation in Québec: The importance of some physiological and ecological characteristics - A review. Forest. Chron. 83: 378-392.

Dumais, D. and M. Prévost. 2008. Ecophysiology and growth of advance red spruce and balsam fir regeneration after partial cutting in yellow birch-conifer stands. Tree Physiol. 28: 1221-1229.

Dumais, D. and M. Prévost. 2013. L'épinette rouge (Picea rubens Sarg.). In: Le guide sylvicole du Québec (tome 1): Les fondements biologiques de la sylviculture. Ouvrage collectif sous la supervision de B. Boulet et M. Huot, Min. Res. Nat. Québec. Les Publications du Québec, pp. 128-131.

Dumais, D. and M. Prévost. 2014. Physiology and growth of advance Picea rubens and Abies balsamea regeneration following different canopy openings. Tree Physiol. 34: 194-204.

Dwyer, L.M. and G. Merriam. 1981. Influence of topographic heterogeneity on deciduous litter decomposition. Oikos 37: 228-237.

Farrar, J.L. 1996. Les arbres du Canada. Les Éditions Fides, 502 p. Frank, R.M. and B.M. Blum. 1978. The selection system of silviculture in spruce-fir stands - Procedures, early results, and comparisons with unmanaged stands. For. Serv. Res. Pap. NE-425, USDA For. Serv., Northeast. For. Exp. Stat., Broomall, PA, 16 p.

Fraver, S., R.G. Wagner and M. Day. 2002. Dynamics of coarse woody debris following gap harvest

in the Acadian forest of central Maine, U.S.A. Can. J. For. Res. 32: 2094-2105.

Greenwood, M.S., C.L. O’Brien, J.D. Schatz, C.A. Diggins, M.E. Day, G.L. Jacobson, A.S. White and R.G. Wagner. 2008. Is early life cycle success a determinant of the abundance of red spruce and balsam fir? Can. J. For. Res. 38: 2295-2305.

Grondin, P. and A. Cimon. 2003. Les enjeux de biodiversité relatifs à la composition forestière. Min. Res. Nat. Faune Parcs Québec, Sainte-Foy, QC, $200 \mathrm{p}$.

Harmon, M.E., J.F. Franklin, F.J. Swanson, P. Sollins, S.V. Gregory, J.D. Lattin, N.H. Anderson, S.P. Cline, N.G. Aumen, J.R. Sedell, G.W. Lienkaemper, K. Cromack and K.W. Cummins. 1986. Ecology of coarse woody debris in temperate ecosystems. Adv. Ecol. Res. 15: $133-302$.

Hyppönen, M., V. Hallikainen, J. Niemelä and P. Rautio. 2013. The contradictory role of understory vegetation on the success of Scots pine regeneration. Silva Fenn. 47 article id 903. 19 p.

Kenefic, L.S., M. Bataineh, J.S. Wilson, J.C. Brissette and R.D. Nyland. 2014. Silvicultural rehabilitation of cutover mixedwood stands. J. Forest. 112: 261-271.

Klein, R.M., T.D. Perkins, J. Tricou, A. Oates and K. Cutler. 1991. Factors affecting red spruce regeneration in declining areas of Camels Hump Mountain, Vermont. Am. J. Bot. 78: 1191-1198.

Kneeshaw D.D. and M. Prévost. 2007. Natural canopy gap disturbances and their role in maintaining mixed-species forests of central Quebec, Canada. Can. J. For. Res. 37: 1534-1544.

Man, R. and K.J. Greenway. 2011. Effects of artificial shade on early performance of white spruce seedlings planted on clearcuts. New For. 41: 221-233.

Morgenstern, E.K. and J.L. Farrar. 1964. Introgressive hybridization in red spruce and black spruce. For. Tech. Bull. 4, University of Toronto, Faculty of forestry, Toronto, ON, $47 \mathrm{p}$.

MDDELCC (Ministère du développement durable, de l'environnement et de la lutte contre les changements climatiques). 2015. Normales climatiques du Québec 1981-2010. Station Honfleur (www.mddelcc.gouv.qc.ca/climat/normales). 
Nyland, R.D. 2002. Silviculture: Concept and Applications, Deuxième édition. McGraw-Hill, New York, 682 pp.

Örlander, G., P. Gemmel and J. Hunt. 1990. Site preparation: a Swedish overview. For. Can. and British Columbia Min. For. FRDA Rep. 105, 61 pp.

Pauley, E.F. 1993. The influence of episodic reproduction by red spruce on long-term forest dynamics in the Cranberry Wilderness, West Virginia. Ph.D. Dissertation, Univ. of Tennessee, Knoxville, $167 \mathrm{p}$.

Perkins, T.D. 1991. Gap expansion, seedling regeneration, and microclimate in a disturbed montane red spruce - balsam fir forest in northern Vermont. Ph.D. Diss., Univ. of Vermont, Burlington, VT. Place, I.C.M. 1955. The influence of seed-bed conditions on the regeneration of spruce and balsam fir. Bull. 117, Can. Dept. North. Aff. Nat. Res., For. Br., For. Res. Div., 87 p.

Prévost, M. and L. Charette. 2015. Selection cutting in a yellow birch-conifer stand, in Quebec, Canada: Comparing the single and two hybrid methods using different sizes of canopy opening. For. Ecol. Manage. 357: 195-205.

Prévost, M. and D. Dumais. 2003. Croissance et statut nutritif de marcottes, de semis naturels et de plants d'épinette noire à la suite du scarifiage : résultats de 10 ans. Can. J. For. Res. 33: 2097-2107.

Prévost, M. and D. Pothier. 2003. Partial cuts in a trembling aspen - conifer stand:

effects on microenvironmental conditions and regeneration dynamics. Can. J. For. Res. 33: 1-15.

Prévost, M., P. Raymond and J.-M. Lussier. 2010. Regeneration dynamics after patch cutting and scarification in yellow birch conifer stands. Can. J. For. Res. 40: 357-369.

Raymond, P., S. Bédard, V. Roy, C. Larouche and S. Tremblay. 2009. The irregular shelterwood system: Review, classification, and potential application to forests affected by partial disturbances. J. Forest. 107: 405-413.
Robert, E., S. Brais, B.D. Harvey and D. Greene. 2012. Seedling establishment and survival on decaying logs in boreal mixedwood stands following a mast year. Can. J. For. Res. 42: 1446-1455.

Ruel, J.-C., D. Lousteau and M. Pineau. 1988. Relations entre la microtopographie, les caractéristiques de la couverture morte et la répartition des essences dans une érablière à Bouleau jaune. Can. J. For. Res. 18: 1196-1202.

Seymour, R.S. 1995. The Northeastern region. In J.W. Barrett (editor). Regional silviculture of the United States, $3^{\text {ème }}$ édition. Wiley and Sons, New York, pp. 31-79.

Smallidge, P.J. and D.J. Leopold. 1994. Forest community composition and juvenile red spruce (Picea rubens) age-structure and growth patterns in an Adirondack watershed. Bull. Torrey Bot Club 121: 345-356.

Takahashi M., Y. Sakai, R. Ootomo and M. Shiozaki. 2000. Establishment of tree seedlings and water-soluble nutrients in coarse woody debris in an old-growth Picea abies forest in Hokkaido, northern Japan. Can. J. For. Res. 30: 1148-1155.

Weaver, J.K., L.S. Kenefic, R.S. Seymour and J.C. Brissette. 2009. Decaying wood and tree regeneration in the Acadian Forest of Maine, USA. For Ecol. Manage. 257: 1623-1628.

Westveld, M. 1953. Ecology and silviculture of the spruce-fir forests of eastern North America. J. Forest. 51: 422-430.

White, P.S. and C.V. Cogbill. 1992. Spruce-fir forests of eastern North America. In: C. Eagar et M.B. Adams (eds.). Ecology and decline of red spruce in the eastern United States, pp. 3-39. Ecological Studies 96, Springer-Verlag, New York. 